\title{
CORTE BESCHRIJVINGE
}

YaX:

\author{
"T EIJLAND JAVA,
}

DERSELVER PROVINTIEN, LANDDEELINEE, RIJCKDOM

EN INWOONDERS,

SOODANICH 'T SELVE NU BEVONDEN ENDE GEREGERRT WERT:

Het eijland Java legt met het Zujjdelijckste eind omtrent 't Kicekenshoofd aen de Westrijde van de straet Balambanghan, op de Zujijderbreedte van 8 graden 47 minuten, en met sijn Noordelijksto uijtstetckende punt omtrent Sedarij, beoosten de hoeck van Crawangh, op de Zuijder breedte van 5 graden 46 minuten, maeckende alsoo besuijden en benoorden een distantie van 45 mijlen, hoewel recht $\mathrm{Z}$. en N. of 't breedste maer 30 mijlen, ende op 't smalste ongeveer 14 mijlen breed. Streckende sich regt W. ten N. en O. ten Z. niet minder dan 140 mijlen in de lenghte, aenvangende aen 't Westelijxte eijnde omtrent 't Princen-eijland, met de lenghte van 124 graden 40 minuten, tot de Z. O. hoeck van de straet Balij, de lenghte van .. graden .. minuten; maeckende alsoo een langhwerpige gedaente van een tashaeck ofte timmermans handsaech, grensende in 't Zuijden met den oceaen, daer het om de groote stortinge van de aenpersende zee maer op weijnich plaetsen navigabel geoordeeld wert; in 't Noorden met de binnenzee tusschen 't groot eijland Borneo en Java; in 't Oosten met de straet gelegen tusschen Balij en Java, en ten Westen met de straet Sunda, tusschen Sumatra en Java, zijnde alsoo rondsom navigabel en vaerbaer; voorsien aen de Noordzijde met diverse bequame havens ende welgelegen eijlandekens, voornaemenlijck Batavia en Bantham, die gehouden werden voor de beste reeden, die elders ter werelt moogen gevonden werden. Dit 
eijland. Java heeft over 80 jaeren nogh bestaen in 14 vrije provintiën, over ijder gebiedende een Pangeran ofte Koninck; namentlijck Balambanghan, gelegen tegen 't eijland Balij, en Sourabaija, aen de Noordzijde. in 't Westen daer aen palende, achter den inham van Madura; Tuban, Patij, Damack, Pamalangh, Cheribon, Jacâtra en Bantham, dewelcke in 't Westen de geheele Noordzijde langs de zeekant, van 't Zuijdelijckste eind van Balij, omtrent het Kieckenshoofd aff, tot het Noordwestelijekste eind, omtrent den inham van Wijnkoopsbergen toe, vervolgens beslaen; comende alleen Balambanghan, Bantham en Jacâtra dwars over 't geheele eijland, doch d' andere provintiën scheijden in het hooge landt, ongeveer 7 tot 14 mijlen van 't Noorderstrand aff, tot het naest gelegen hooghgeberchte, blijvende alsoo een groote landstreeck in 't Zuijden overig, die in 't Oosten paeld met Balambanghan, in 't Westen met Jacâtra, in 't Noorden met Cheribon, Pamalangh, Damack, Patij, Tuban en Sourabaija, ende in 't Zuijden met den grooten Oceaen; dewelcke door een seer machtige aenstortinge van de Zuijdzee het strandt daer onbruijckbaer maeckt, om eenigh cleijn ofte groot vaertuijgh te connen gebruijcken, ende als een muer die zijde van alle vijanden affsluijt; gelijck ick persoonlijck met verwonderinge 't selve gesien heb. Dese landstreeck niet minder dan 100 mijlen lang en op het smalst 7 tot 18 mijlen breed, was verdeelt in 5 provintiën, de volckrijckste ende gesegenste van alle, genaemt Porbaija, Blitar, Selaron, Crappia ende Matâram, leggende Matâram in 't midden, grensende in 't Oosten Porbaija ende Blitar, in 't Westen Crappia ende Selaron; gebiedende over ijder deser provintiën een Koninck, onder den tijtel bij haer van Pangeran, soodanig meede gelijck de andere aen de Noord, Oost en Westzijde voor gemeld. Dese 14 provintiën zijn noch hedendaeghs met seer schoone verse rivieren van malcanderen tot limietscheijdingen affgedeeld, ende behouden haer oude jurisdictiën, naemen ende inwoonders, soodanich UEd. in 't vervolch van deesen, raeckende Jacâtra, nader gelieven te sien.

Het binnenste landt van Java is meerendeels berchachtig, daer van eenige seer hoogh, doch ten aensien van 't groote land seer weijnich die onbruijckbaer, niet bewoond en gecultiveert zijn; welcke geberchten dan oorsaeck zijn van soo veel rijcke en schoone rivieren, soo meenichvuldig 
door 't geheele land verspreijt, als bij comparatie des menschen ligchaem met aderen; alle meest met uijtmuntent goed en christalijn blanck waeter, behalven de natuerlijcke fonteijnen en springwaeteren, die in de 5 binnenlandse Zuijder provintiën abondant gevonden worden, soodanich dat in de Matâram meest alle de vermogende heeren een stroom door hunne huijsen hebben loopen, daer in de nature door leijding wat geaccomodeert is.

Het climaet van Java is doorgaens seer gesond; doch voornaementlijek in de gemelte 5 provintiën, die alle met ongeloofflijcke schoone landen verciert zijn, in vruchtbaerheijd geen landen ter werelt hebbende te wijcken; inwendich van soo heuchelijeken aensien, dat ick verclaere in India nooijt schoonder land gesien te hebben, nae mijn oordeel alle d'andere overtreffende, exepto China en Japan, die ick nict gesien heb en voor uijtmuntende landen bekend zijn. Dat het climaet gesont zij, blijckt daer aen, dat de Javaenen doorgaens, soo wel mannen als vrouwen seer oud worden, hoewel van hun 12,13 en $14^{\text {de }}$ jaeren de mans al seer luxurieus bevonden worden, en selffs in hunnen hoogen ouderdom geen saecken ter wereld meer estimeeren als 't minnespel. De provintiën langs de zee aen de Noord, Oost en Westzijde gelegen, zijn dicht aen de zeeçant soo gesont niet, om de moerassige gronden in de winter ofte regentijd, doch meer voor de vreemdelingen als de inwoonders, omdat de. rivieren door den gestadigen regen en 't aenpersen van ' $t$ zeewaeter de lage landen veeltijds onder setten, ende de son besuijden de linie zijnde hun meest recht booven 't hooft schijnd ende veel quade dampen uijt de omsijnde poelen optreckt, die dan de vreemdelingen coortsen en andere sieckten placht te veroorsaecken; ende is oock op 't gansche land geen moerassiger gront geweest, als daer Batavia wel eer placht te leggen, dat door continueelen arbeijt (God loff) soo verre verwonnen is, dat present die plaets niet ongesonder can gehouden worden, als een der beste provintiën, zijnde tegenwoordich Bantham alleen het ongesondste van allen.

De vruchtbaerheijd deses eijlands bestaet in d'overvloedigheijd van den rijst. Allerleij fruijten die ergens in India mogen zijn ofte connen gevonden werden, gelijck oock veel Europische en andere zaden, daer 
terstont voortteelen, een ijder genoegsaem kennelijck zijnde, dat anno 48 alleen op Batavia aengebraght is, niet minder dan 6000 lasten rijst, behalven noch die van andere plaetsen van daer vervoert werden.

De rijckdom deses eijlands is ongelooffelijek, hebbende de nature buijten goud en silver daer alles geplant, wat de menschen op aerden van Godt de Heere soude mogen wenschen, jae oock soo overvloedich als elders eenig land hebben mach; bestaende deesen overvloed specialijck in allerleij eetwaeren, als rijst, boonen, erwten en diergelijcke granen. Dat er geen tarwe zij is onse eijgen schuld, die sonder twijfel daer groeijen sal, sulcks aen de beginselen genoegsaem gebleecken zijnde. Item allerleij beestiael, als buffels, coeijen, schapen, bocken, herten, hinden, steenbocken, varckens, gansen, eendvogels, hoenderen, duijven, tortelduijven, alles tam en in soodaniche menigte, dat men in een van de landprovintiën een koebeest om 5 gulden, item $40,50,60$ à 70 hoenders voor drie gulden can coopen, alle 't ander naer advenant. Item seer veel wild is daerenboven in de bosschen, als uijtnemend veel herten, hinden, wilde coebeesten, varckens, steenbocken; veelderleij gevogelte, als duijven, tortelduijven, craenen, reijgers en diergelijcke, doch buijten dese is er weijnich cleijn gevogelte, in comparatie als wel op de vaste landen van India gevonden werden. Boven deese eetwaren zijn de landen nog overvloedig van schoon timmerhout voorsien, soodanich dat ick door bosschen gereijsd heb, daer men 50 à 60,000 swaere boomen van 40,50 en 60 voeten langs den stam, en 15 à 20 duijmen in diameter dick, soude daeruijt gehackt hebben, sonder eens te verneemen dat er hout gehaelt was, gaende dit bosch bijna door 't geheele eijland van 't Westen tot het Oosten en op 't minste wel 4 à 5 mijlen breed: daer uijt de quantiteijt aff te meeten zij. Boven dit is 't lant noch voorsien van catoen, peper, lange peper en cubebe, gember, suijeker, soo veel als men begeert aen te planten, item swavel en salpeeter in sulcken overvloed, om jaerlijex heele scheepen te cunnen laden, daervan ick selve de mijnen gesien heb. De geberchten zijn oock vol alderhande steenen, als arduijn en diergelijcke om schoone timmeragiën en langdurende wercken van te maecken, de materie tot calck op geen plaets ter werelt minder dan hier ontbreeckende. Alleen, als gesegt, ontbreecken hier de 
mineralen van goud, silver, coper, ijser, lood, thin, enz., dat aldaer nochthans door den overvloed van andere dingen overvloedig genoeg aengebracht werd. Echter can ick niet naelaten UEd. te verseeckeren dat het goud aldaer uijt overoude graven in tamelijcke quantiteijt opgegraven ende gevonden werd, soodat het goud daer seer abondant is, blijckende, dat, die iets van staet zij, allen gouden hechten op hun crissen draegen, en veel goud in de crissen en hunne piecken indrijven, daermede seer veel geconsumeerd werd. Ick heb aldaer oock diverse mael 't goud sien vercopen in quantiteijt van 3 à 4 pont tot 8 à 9 rèaèl in specie den reael swaerte, van seer goet alloij, en is 't buijten twijfel dat niemant voor die prijs van buijten goud inbrengen can. Niettemin weten de Javaenen geen reedenen te geven dat er ergens goud valt, dan in dese gemelde graven, daer het van veel menschen gesocht en gevonden werd, bestaende meest in armringen, vingerringen ende ander sieraed, tot 's menschen ligchaem nae hunne oude wijse dienstig geweest zijnde. Dese opgedolven graven hebbe ick persoonlijck diverse maelen gesien, ende dat zij nog met soecken besich waren.

Hoedanich dit eijland tot den handel van geheel India gelegen legt, is onnodig UEd. te vertoonen, zijnde mijns oordeels soodanich dat het niet beter can bedacht worden, en of wel sommige willen sustineeren van Banca ofte andere plaetsen, zoo comt hetselve niet eens in comparatie, om veijlig 't geheele jaer ende alle dagen aff en aen te vaeren, ende om de costelijcke geladen schepen voor alle bedenckelijke disastres te preserveeren; behalven 't sluijten van den pas door de straet Sunda, en de gelegenheijd om de Oosterse costelijcke landen te beschermen, generalijck van sulcken constitutie zijnde, dat de geene die heer van dat eijland zij, door goede politie, macht en vermogen heeft, om van ieder gevreest ende t' zijnen voordeel aengesocht te worden.

Ende of wel God de Heere dit eijland met groote vruchtbaerheid ende alles wat den mensch tot onderhoud deeses tijdelijeken levens van noode zij, gesegend heeft, soo wert hetselve nochtans bewoont van seer boose en ondanckbare menschen, gewisselijck en ongetwijfelt een oud, louter, eijgen en natuerlijck volck, die geen aff komst of gemeenschap met d' aengrensende eijlanden hebben, maer door Godt de Heere aldaer uijt 
een geslacht (die ick om haer ongelooffelijeke boosheijd voor eenige Chams kinderen houde) doen voortteelen. Dit blijckt aen hunne sprack, weesen, gedaente, maniere, zeeden en eendrachtige nature, van de aengrensende eijlanden seer verschillende, item aen hun schrift, met geen menschen op den aerdbodem gemeen. Dat het seer oud volck is bewijst meede hunne oude comediën, geschriften, ende 't verhael van veel ouder tijden, dan eenige van de Maleijers, Balijers, Macassaren, Amboijneesen, Molucaenen, Borneoten, Sumbawers, Soloreesen, die alle Maleijsch schrijven; 't welck de Maleijers nu naeuwelijcks over 100 jaeren van de Arabieren en Mahomedanen, gelijck mede hunne godloose secte, geleerd hebben, die door hunne vaert ende frequentatie met de gemelde eijlanders hun 't schrijven ende met een 't gelooff ingeprent hebben; die voor deesen geen van allen hebben connen schrijven, gelijek noch onder honderd Maleijers naeuwelijcks vier gevonden werden die schrijven connen, ende onder d' andere naeuwelijcks twee; daerentegen weeten de Javaenen geen tijd hier van te reeckenen, en cunnen de meeste menichte alle schrijven en lesen.

Deese Javaenen zijn van schoone, gedrongen, musculeuse en frissche gedaenten, ordinair wel 100 vette tegen 10 magere, hebbende doorgaens een schoon ligchaem, geproportioneerd op welgemaeckte beenen, dick van kuijten, en smal van encklauwen versiert; nochtans met een leelijcken cop, bewassen met ongeloofflijck schoon hair, soo dat se van achteren gesien zijnde, representeeren een schoone gestalte, maer van voren een plat affzienelijck aengesicht: nochtans den een veel meer als den anderen; van couleur d' arbeijders bruijn geel, ende die van staet en vermoogen redelijck blanck geel. Het vrouwrolck is doorgaens veel schoonder, eer mager als vet, voornaementlijck die in de heerenhuijsen zijn, die ordinair schoon, jae, veel welcke blanck en seer wel besneeden zijn, seer tenger van ligchaem, smal van middel, lang van armen en vingers, die de groote heeren van vermoogen seer wel weeten uijt te cippen, op soodanige plaetsen als een ieder onder zijn gebied vinden can.

De regering over al deese landen en volckeren heeft voor omtrent 80 jaeren als gesegt bestaen in 14 Pangerans, ieder den naem dragende over zijne provintie, ende was deesen present regerende Koninghs groot- 
vader genaemt Pangeran Crappia, gelijek mede den laetsten overleden Koninck (eer hem de naem van Sulthan uijt Mecca toegebracht ende vereert was) genaemt geweest zij. Desen Pangeran Crappia gebijnaemt Ingalaga (dat is strijtbare) was den derden Pangeran, die, omtrent 't jaer Christij 1576, de Mohametaensche secte heeft aengenomen : den eersten den Banthammer, den $2^{\text {den }}$ den Cheribonder zijnde; en dewijl zijn geburen nae zijn oordeel hardnecklijck weigerig waeren, met hem dese religie aen te neemen, maeckte sich terstond tot den oorlog gereed, hebbende onder zijn restrict daertoe magt en vermogen, tastende eerst aen de magtigste, volckrijckste ende vruchtbaerste provintiën van alle, genaemt Matâram, die hij in corten tijd overwonnen hebbende, bragt terstond met groote wreedheijd om alle 't Konincklijcke geslacht met hunne dienaers, sonder vrouwen ofte kinderen te spaeren; voerende terstond daermeede in zijn nieuwe aengenomen religie, ende nam zijn residentie in de Matâram, in een nieuw hoff, dat nae hunne wijse daertoe gemaeckt werd, en ick selff nog gesien heb. Na 't veroveren van deese provintie, heeft hij tot het uijteijnde zijns levens geoorloogt, hebbende voor zijn dood noch heer en meester geweest van de provintie Porbaija, Blitar, Salaron en Pamalangh, grensende tegen Cheribon, daer hij groote correspondentie en goede vreede meede onderhield, sulcks oock al stervend aen zijn zoon recommandeerende, quansssuijs omdat den Cheribonder vór hem 't gelooff hadde aengenoomen ende een heijlige man was. Dese Koninck is gestorven omtrent 1603. Hem succedeerde zijn soon, doenmaels Pangeran Maes genaemt, hoewel hij noch heeden ten dage leeft ende Pangeran noen, Sanjo Porbaija genaemt werd. Desen Pangeran Maes de tijtels en naem zijns vaders aenvaerd hebbende, volgde terstond mede zijne concepten en wapenen, hoewel de andere provintiën nu meede al zijn religie hadden aengenoomen, behalven alleen de Balambangers, en drong van langer hand, eerst Sourabaija met accoord, naderhand Tuban en Damack met wapenen. Doch Patij, een wel gelegen land ter defentie, heeft hij lang moeten beoorlogen, zijnde deesen Pangeran in zijn hoofdstadt Patij geretireert, die hij met een dicken muer liet beschanssen, met een voornemen deesé stadt met het leven te gelijek te verliesen, daer van noch veel liedekens onder de Javaenen gesongen werden, en werd voorseecker gehouden, 
dat deese belegeringe wel 150,000 belegerde ende 200,000 belegeraers, alle mans, 't leven gecost heeft. Eijndelijek, omtrent anno 1620 , is den Pangeran Crappia affgetoogen in persoon, en, nae veel bloedstorten, verwinner gebleeven van 't geheele landt, exepto Jaeatra, Bantham, Cheribon en Balambanghan; omtrent weleke tijt wij meede ( $t^{\prime}$ zijner herten wee) Jacatra innamen, Nae welcke overwinningh den Koninck in de Matâram gekeert zijnde, heeft aldaer beroepen alle de overheerde Koninghen, die noch in 't leeven waeren, versoeckende insgelijeks zijn bondgenoot den Cheribonder sich in persoon ten hove te vervoegen, die (hoewel ongaerne) uijt vreese gecompareerd is; hier stelde een der grooten voor, dat deesen raed beroepen was, om den Koninck een naem, zijn qualiteijt waerdig, te geven, den naem van Pangeran te gering zijnde, als gemeen met andere heeren zijne onderdaenen, en die hier de beste naem bedacht soude verheeven ende verheerlijckt werden. Een der grooten nam seeckeren dach waer, dat den Koninek te voorsehijn kwam, ende deede aldaer met groote eerbìedigheijd een oratie over 's Koninghs groote daden, waer over hem toekwam den naem Sousouhounan Ingalaga Matâram, ofte de hoogste off opperste strijdbare Vorst, beteeckenende in de Javaense tael een zeer arroganten eertijtel, als ofte ter wereld geen grooter te vinden was, ende 't woord Matâram niet meer, als dat zijn hoff daer zij. Desen naem hebben alle grooten gepresen, ende den Koninck deselve opgedragen, sich alle onder zijne heerschappij buijgende, die den Koninck met een stilswijgend toeknicken nae hunne wijse aennam; vereerende den naemgever met den tijtel van Râdin Aria Wiera Nâta Pâda, off onder-prince verstandig boven andere; hem daerenboven met landen en volck onder zijn heerschappije begiftigende; en om onderscheid te maecken tusschen de overheerde Koninghen ende den Pangeran van Cheribon, soo gaff hij mede aen den Pangeran Cheribon de naem van $\mathrm{Pa}$ nambâhan Cheribon, dat is in substantie, een heere die men sonder reverentie niet genaecken mach, ende liet denselven nae goed onthael en aengedaen tractement wel vernoegt vertrecken, maer d' andere werden belast bij hem ten hove te verblijven. Zijnde toen noch in 't leven den Pangeran Sorbaija (die ick in de Matâram noch gesien ende gesproockẹn hebbe), Pangeran Toeban ende de descendenten van alle de andere Pan- 
gerans; exepto van Patij en Matâram, wiens geslachten totaliter uijtgeroeijt waeren. Welcke descendenten eenige de eernamen cregen van hunne vaderlijcke affcomst, mitsgaders de incomsten van hun land, soo veel den Koninck hen toelejjde, maer bleeff de regeringe onder des Sousouhounans macht, die tot een preuve van zijn wraeckgierigheijd, eerst de stadt Patij van zijn muren deedde ontblooten, daer van ick de ruijne selver gesien heb, ende sond toen een magtig leger onder seeckeren Tommagon Wiera Goena, om 't eijland Madura te dwingen, dat hem eijndelijck geluckt is, voerende desen Wiera Goena den Pangeran ende alle zijn geslacht naer booven in de Matâram, die nevens d' andere aldaer een plaets is aengeweesen om hun hoff te houden. Omtrent dien tijd, dat soo veel mij hebbe connen informeeren geweest zij anno 1624 , hebben de Portugesen van Malacca de Javaenen de cunst geleert van selver buscruijt te maecken, 't welck zij te vooren van de Portugesen moesten coopen ofte voor rijst en andere coopmanschappen rujjlen, hebbende deese Portugesen met eenen aengeboden de Javaenen te helpen om Batavia weder te winnen, daer den Sousouhounan sonderlinge al eenige jaeren toe geinclineert hadde, ende van nu aff voornam, 't selve in 't werck te stellen, daertoe hem de Portugesen (doenmaels noch in macht en haer fleur zijnde) diverse metale stucken hebben vereerd, daer onder twee die ick in de Matâram gemeeten hebbe, niet min dan 15 voeten langh, te weten schietende 16 à $18 \AA$ cloots. Behalven dat deese verradersche Portugesen ons seer schendich defameerden voor tovenaers, die met de duijzels omgingen, en andere quaed gebroed van menschen; dat soodanig oock in deeser menschen herten was ingeworteld, dat als den coopman Jan Hermansen, anno 47, aen den presenten Koninck gesonden werd, hij den selven niet heeft moogen sien, maer is hem verthoont een van de grooten, genaemt Radin Aria, als ofte dit den Koninck in persoon was. Want men had den Koninek wijs gemaeckt, dat wij soo behendig, 's Koninghs aenschijn siende, die beeldtenis na 't leeven conden affconterfijten, en dan dat conterfijtsel soodanig tracteeren, als wij begeerden dat den Koninck soude gesteld worden, 't zij in humeur, sieckte, dood en diergelijek het ons behaegde. Doch desen Radin Aria de proeff daervan uijtgestaen hebbende, heeft sich den Sousouhounan 
naderhant met der tijt-seer familliaer omtrent $d$ ' onse bethoont, ende mij selver in persoon dit verhaeld, hoe dat door quade menschen zijn vader ende hij meede een tijdlang geinduceerd geweest zij. Den Sousouhounan nu anno 26 meest vaerdig zijnde, om zijn concept uijt te voeren, heeft in de Matâram een groote affheijning ofte een sterck jatijhouten heck doen maecken, tegen zijn hoff aengrensende, ende aldaer beroepen tot een vergaderingh alle de heeren van 't land, die ' $t$ gebied hadden over zijn volck van oorloge, ende dat een ieder zijn macht soude meede brengen; alwaer binnen seer weijnich daegen gecompareert zijn omtrent 900,000 volwassen mannen, de minste gewapend met een pieck, ende een cris ofte gevlamde poock, soodanig mij van de Nederlantsche gevangens eendragtig verhaeld ende versekerd zij; maeckende de Javaenen dit getal wel eens soo groot. De Koninck deede onder dit volck werpen 10 ofte 12,000 Spaense realen te grabbelen, ende seijde dit zijn geheele schat to weesen, begeerende gelijck hij alle zijn rijckdom haer hadde uijtgedeelt, zij insgelijx alle haer krachten ende vermogen moesten inspannen om Batavia uijt der kafirs handen te ontweldigen, kiesende uijt den hoop der grooten seeckeren Tommagon, Bouraxa genaamd, die met 60,000 mannen uijt deesen grooten hoop gekoosen, aennam Batavia te winnen ofte 't leven te verliesen, en gevolgelijck anno 28 voor Batavia 't leger gebracht ende 't leeven verlooren; keerende naauwelijeks 't vierdepart van 't leger weder terug, die meerendeels noch door 's Koninghs last zijn doodgeslaegen, waer men se vond. Den eersten tocht misluckt zijnde, heeft. hij terstond zijn voornemen vervolgt, ende andere 80,000 , onder eenen Tommagon Singeranou en diverse andere grooten gesonden, die anno 1629 voor Batavia comende, minder als de eerste heeft uijtgeregt, zijnde niet meer dan omtrent 10 à 14,000 die der 't leeven aff brachten. Want de grootste helft door sieckte, honger, 't swaerd, enz. omgecomen zijnde, heeft den Sousouhounan alle de passen doen besetten, met order dat niemand tot zijn vrouw ofte kinderen soude keeren, maer dat men se alle doodslaen soude, soo wel groote als cleijne, dat meerendeels alsoo g' effectueert is; uijtgesondert deesen gemelten hoop van 10 à 14,000, die den Tommagon Singeranou wel gewrapend en op hoede bij sich hield; zijnde meerendeels zijn eijgen 
volek, hem weleer van den Koninck nae haer wijse $t^{2}$ ondergesteld, ende onder 't restrict van zijn leenlanden bescheijden. Met deese macht treckt hij gecombineert door alle de passen, doodslaende die hem in zijn voornemen beletten wilden, tot in de Matâram ende binnen zijn woonhuijs, ende, sich vertrouwende op de groote gunst des Koninghs, send terstond alle zijn vrouwen, bijwijven en kinderen naer 's Konings hoff, om den Koninck aen te dienen, dat zij daer gesonden waeren om 's Koninghs gramschap aen te boeten; met haer sendende alle de waepenen van hem ende den geheele hoop, die sich onwaerdig kenden Zijne Majesteijt aen te schouwen, maer bleven bij malckanderen om naer 's Koninghs believen geslacht te werden. Dit scheen den tiran te vermorwen en van opset te doen veranderen, daartoe noch meer hielp, dat een van zijn alderschoonste en lieffste wijven desen Tommagon Singeranous dochter was, die al lang voorheen van des vaders voornemen kennisse gehadt hadde, ende ter gelegener tijd den Sousouhounan bewogen, dat hij doch haer vaders huijs wilde genadig zijn. Den Koninck nu inderdaed doen verneemen hebbende, dat sich deesen oversten in een affschutting beslooten, ende selver met alle zijn volck armen en beenen hadde doen binden, verwachtende de dood, liet zijne vrouwen ende kinderen naer huijs keeren ende den oversten zijn macht ende waerdichheijd behouden, hoewel in geen drie jaeren onder 's Koninghs oogen mogt comen; dewelke verstreecken zijnde, heeft hij 't hoff als voorheen gefrequenteerd, ende bevestigde men nu noch meer als vooren, dat wij als tovenaers niet te dwingen waeren, en heeft men van toen aff gedespereert om ooit heer van Batavia te worden. De hoocheijd van den Koninck is niettemin middelerwijl in eertijtelen aengewassen, want de Engelsche van Japara, vervoerende eenige hunner paepen naer Suratte, van waer deselve met Moorsche scheepen naer Mecca, aen 't gepretendeerde heijlige graff des verleijders Mohamet, gevoert zijnde, en hunne gaven offerende, zijn met een Arabier weder behouden te huijs gekeerd, den Koninck in vergelding van zijne oncosten den eernaem brengende van Sulthan Mohamet, gelijk oock om die tijt den Banthammer den naem creeg van Sulthan Abdul. Den Koninck met dese naem ten hoogsten vereerlijckt, prepareert een nieuw gesantschap van over de hondert jonge 
edelen, alle der grooten kinders, met zijne geretourneerde paepen vergeseld, om met de Engelsche andermael de reijse te hervatten, ende danckbaer aen 't heijlige graff te wesen. Deesen zijn (gelijk UEd. bekend zij) anno 1642 van d' onse achterhaeld en omtrent Batavia geligt, met alle de buijt, op hope dat den Koninck met restitutie van al den vervoerden schat, heilige paepen en edele kinders soude bewoogen worden onse ellendige gevangens daer te relaxeren, dat echter niet heeft willen vallen, maer heeft ' $t$ selve eer een voorbeeld veroorsaeckt van de nature deeser wreede menschen; want den Koninck in plaets van nae deese billijcke en redelijcke conditie te luijsteren, liet terstont alle de gevangens, die onbesneeden ofte nae hun wijse geen vrouwen hadden willen trouwen, seer ellendig cluijsteren, armen en beenen met stocken knevelende, ende den hals needergeboogen bindende, ende 't hoofd van hen allen, zijnde den ondercoopman Anthonij Paulo, van den hoop affsepareren, met sodanigen manier van boeijen, dat de duijvels in de helle (nae manier van 't spreeckwoort) geen wreeder soude hebben cunnen practiseeren. Dus gekneveld wert den onnoosele mensch beschuldigd van toverije, die, met brieven door de lucht gevoerd, de Hollanders op Batavia hadden gewaerschouwt, om op deese gesanten te passen; ende ofte wel deese man de reedenen, 't recht, de waerheijd ende alle rechtmatige middelen t' zijner verdading crachtelijck bijstonden, soo bleeff hij toch, in 's Koninghs oordeel, den tovenaer die hun verraden had; die nae lange quellingen veroordeeld werd in secckere poel geworpen te worden, daer men caijmans ofte crocodillen in voedde, om justitie te executeeren, naer 's Koninghs believen sulcx meriteerende; ende dewijl it Godt de Heere belieft hierin speciael een groot miraeckel te bewijsen, is 't ten hooghsten noodich zijnen heerlijeken name ende mogendheijd daer over te loven en deese saecke niet te verbergen, maer UEd., jae de gansche wereld, sulex te vertoonen, omdat oock de deugd en godvruchtigheijd van deesen ondercoopman wel verdiend de saecke wat hooger op te halen.

Deesen ondercoopman was gevangen in 't jaer 1631, ten tijde den ouden ontfanger Maseijck zaliger van den Gouverneur-Generael gecommitteert was, om den vreede te sluijten; die geslooten zijnde, ende hun geschenck weg hebbende, zijn d'onse onbecommert, op ' $t$ volekerenrecht 
vertrouwende, naer land gevaeren. Echter gemelde Maseijek, daer 't verraed meest op aengelegd was, kwam (als die humnen aerd wel kende) nooijt aen land, maer sond telekens deesen Anthonij Paulo, een godvreesende, actijff ende seer verstandige borst, professie doende in onse ware gereformeerde religie; dewelcke ten laesten met noch 25 andere aengehouden ende seer verraderlijck naer de Matâram gevoerd wierden, daertoe ' $t$ volck van't verongeluckte schip Schiedam ende andere al gevangen saten, latende den Koninck dit onderscheijd, dat deese vrij door de stadt mogten loopen, om hun cost te soecken, hun noemende zijn eijgen gevangens, daer d' andere als oorlogsgevangens onder meesters verdeeld, swaer werck moesten doen. Deesen Anthonij Paulo, siende dat eenige van de voorige wijven hadden ende 't Moorschdom uijt dwangh toegevallen waeren, creeg daeraff een groote affschrick, ende om daerin met wijsheijd ende couragie te voorsien, deed sich van zijne 25 meedegevangen erkennen voor hun hoofd en leermeester, sich met hun tot alle arbeijd om de cost te winnen als d' jjverigste inspannende, maer des avonds, 's morgens en sondags, als hun tuchtmeester, predicant ende vertrooster, somwijlen die 't verdiende sonder simulatie doende straffen, naer ejjsch van saecken met snelle rottang slaegen, voerende selver soo godsaligen leeven, dat hij in corten van alle de gevangens hartelijck bemind was, die enckel begeerden, dat hij niet soude wercken, waertoe hij nooijt to brengen was. Zijn behendig verstand deed hem vóór alle andere de Javaensche costumen, hun lesen, schrijven en andere noodwendigheden, soo wel leeren, dat hij in corten tijd booven de Javaenen selfs uijtmuntte om harten te winnen tot zijn persoon, waerdoor hij onder de Javaenen seer geëerd ende gepresen was, soo dat iemand der zijnen iets misdoende, zij bij hem kwamen claegen, daer hij altoos 't recht nae zijn uijtterste vermogen voldeedt, emploijeerende altoos zijn geoptineerde gunst tot voordeel van zijn meedegevangenen, sonder onderscheijd van de gevangene van oorloge ofte zijne onwettige. Soo dat hij genoegsaem als hun capiteijn, van de Javaenen in groot aansien gehouden werd, ter tijd toe dat hij, als gesegd, door 's Koninghs bevel, volgens gebruijck, aen den oever tot de middel toe in 't waeter gestelt $z$ ij, om van de onbarmhartige crocodillen verslonden te werden, die tegens natuer, in 't 
aensien van onse gevangens en duijsende Javaenen, aen 't ligchaem kwamen rüjcken, ende doocken terstond weder weg. Dit duerde aldus drie gehcele etmaelen. Middelerwijl gaff men deese beesten niet te eeten, ende sat den ellendigen, God biddende hij wilde doch de beesten de mont openen ende cracht geven hem te verslinden; maer 't schijnt dat het den Heere niet belieffde. 't Welck eijndelijck den Koninck aengedraegen zijnde, seijde deesen onmenschelijcke barbaer, datter geen claerder bewijs van zijn toverije conde blijcken, belaste derhalven; capt hem aen stucken en smijt de stucken in 't waeter, en siet hoe zij hem sullen opslocken. Dat terstond volbracht zijnde, bleeven de stucken bovendrijven, sonder datter ooijt een der caijmans nae taelde, die als rasende van honger malcanderen dreïgden aen te tasten, ende 't gevecht al begonnen. 't Welck den Koninck andermael aengebracht wesende, heeft God de Heere hem gedwongen te seggen, de man was onschuldich, ' $k$ heb hem in mijne toorn doen dooden, gaet, begraeft hem en steld zijn onschuld daer bij. Daermede de stucken in een kist gelegd zijnde, zijn deselve begraven, ende stelde men een viercant heckjen om 't graff, ende een dack daer over, zijnde een eere die ordinair de omgebrachte genieten, daer aff den tiran naemaels rouw crijgt. ' $k$ Hebbe dit heckjen gesien en is mij dese historie eendrachtig van de Nederlantsche gevangenen ende verscheijde Javanen, groote heeren zijnde, verhaelt, die met uijtnemende verwondering daer van noch dagelijeks spreecken, dat dan bij gevolge waerdich geacht hebbe tot loff deses mans UEd. hierin te voegen.

Hoewel dit berouw in menschen, daer schaduwe van redelijckheijd bij zij, den tiran had behooren te bewegen tot relaxatie der gevangens, zijnde hem noch aengepresenteert, dat wij met onse scheepen deese graffbesoeckers wilden overvoeren, soo heeft nochtans de wraecksucht tot de onse grooter geweest, als de affectie tot zijn religie, volck ende geld; latende de zijne op Batavia gevangen blijven, sonder ooijt daer nae te taelen, tot zijne sterffdach toe, die geweest is anno 1645 , latende- van 2 volwassen soonen, den jonghsten tot zijnen successeur, bij hem als den bekwaemsten daertoe opgetoogen, oud toenmaels omtrent 26 jaeren. Dese successie geschiedde gedurende des vaders sieckte, die voor oproer 
onder de gebroeders en hun oom, zijn eijgen oudsten broeder Pangeran Porbaija, vresende, liet alle de voornaemste grooten, daer onder eenen Pangeran en seeckeren Tommagon Wiera Goena wel de voornaemsten waeren, bij sich ontbieden, insgelijcks mede zijn broeder Pangeran Porbaija, en liet de keuse over dese zijnen soon goedvinden, en hield hun alle eenige dagen binnen ' $t$ hoff. Middelerwijl waren alle passen met crijgsvolck beset, ende de meeste macht onder Wiera Goena in de wapenen, die alle 't geschut ende wapenhuijs voor den nieuwen Koninck verseeckerd hield. Den Koninck overleeden zijnde, verthoonde sich den nieuwen terstond met des vaders lijffwacht ter ordinaire audientie, daer hem van alle de grooten met slaeffsche dienstbaerheijd geluck gebooden werd, met den naem van Sousouhounan Ingalaga Matâram. Zijnn oom Pangeran Porbaija droeg hem terstond zijn geslacht van kinderen en kindskinderen op, als zijne dienaeren, die hij, hem als van 't naeste bloed op 't hoogste recommandeerde; insgelijcks versocht hij, dat hij doch zijn ouder broeder niet verwerpen wilde, ende exempel aen zijn vader neemen, die jonger als hij zijnde, nochtans hem altoos hartelijck bemind ende verheeven had. De broeder, die absent was, werd geroepen, die hij sulcx beloofde, hem versoeckende hij wilde hun ooms voetstappen volgen, die hoewel ouder van jaeren nochtans hun vader booven andere geëerd ende tot een goed raedeman verstreckt had. Hierop kwaemen alle de grooten, geen uijtgesonderd, des Koninghs groote teen al cruijpende cussen, die gecust zijnde over hun voorhoofd streijckende, met een groote eerbiedicheijd; maer en begeerde den Koninck sulcx van zijn oom noch broeder niet te gedoogen, te gemoet siende apparent zij daer niet toe gesind waeren. Den Koninck deed hierop naer humne wijse een aensprack tot des vaders oude raedsheeren, die hij boven andere wilde in waerde houden enz., voornaementlijck verhefte hij terstond Wiera Goena (die hij nochtans als de dood haette) ende eenige andere des vaders gunstelingen, daerdoor hij in corten tijt gevest zijnde, werden de passen alle weder open gesteld, de vader begraven met ceremoniën te lang UEd. op te houden. Deesen Koninck, uijt doorluchtiger vrouw gebooren als zijn broeder, was bij de gevangene Nederlanders als een opgaende sonne ende d' uijtwendigste hoop om van hun ellende eens ontslagen te wer- 
den, van zijn kindsbeenen aen seer geëeert; die $6,7,8,9$ jaeren oud zijnde, van hun werd versorgt met Hollands speeltuijch, bij hun nooijt gesien, als vliegers, tollen en diergelijcke, ende seer woest en robust van aerd zijnde, liep met een gesleep van zijn oppassers 't geheele land door, en omdat de Hollanders hem behaegden, nam veeltijds hun mede om tegens zijn volck te worstelen, daer hij groot vermaeck in had. Ende nu tot 14 à 15 jaeren gecomen zijnde, was crachtig geneijgt tot vrouwen, ende door kindse familiaerheijd kwam dickmael d' onse verhaelen, wat hij al uijtgerecht had. d' Onse door 't voorsigtig bestier van den voormelten Anthonij Paulo deese familiaerheid als een costelijcken schat in waerden houdende, en zijn curieusheijd tot groote paerden en diergelijcke siende, presen hem op 't hoogste aen, de vreede met d' Hollanders; immers baden hem soo lange, dat hij soude hun alle vrijlaeten en vreede maecken, enz. Dese beloften onderhielden d' onse gedurich in zijn gedachte, tot dat hij nu Koninck geworden zijnde, drie van zijn liefste .... die hij ooijt onder de Hollanders meest bemind had, deede roepen ende hun aenseggen, gaet een van u drieën naer Batavia ende segt uwen Generael dat hij volck send om met mij vreede te maecken, maer past op mij niet achter te blijven ofte te bedriegen. Daerop dan de vreede gevolgd zij, soodanig UEd. bekend zij. Deesen Koninck is die present noch regeert, ende waeraen ick vijff maelen gecommitteert geweest ben, om de vreede te carresseeren ende aen te houden, een man, mijns oordeels, die 't met ons tot noch redelijck wel gemeent heeft, en die oorsaeck zij, alleen door zijn enckele kennisse aen onse gevangens, dat wij nu voor geen tovenaers meer getaxeert zijn, maer niettemin nae der wolven aerd, alsoo weijnig te vertrouwen als zijn vader. Met zijn thienjaerige regeringe alreede betoont hebbende, dat hij denselven in verstand en beleijt van staetssaecken vrij verre overtreft, ende sulex metterdaet betoont in 't gebieden, dat niemant zijner onderdaenen mach buijtenslants vaeren, maer begeert dat een ijder van buijten zijn land sal comen soecken; wel wetende 't selver de spijsekamer van Batavia ten principalen te wesen, daer door hij dan alles wat d' onse aenbrengen aen sich treckt, sonder dat ijmand der onderdaenen een stuijver mach handelen. Ende om 't geld derselver in sijn casse te trecken, had 
hij eerst 't hoofdgeld op alle de huijggesinnen gesteld, die over 't gansche land beschreeven, geteld ende onder heeren verdeelt zijn, op ijder een reael van $8^{\text {ten }}$ des jaers. Die nu niet hebbende (als genoegsaem waerachtich zij, datter soo veel realen in 't geheele land niet geweest hebben) moeten ijder huijsgesin opbrengen 10 groote bossen padij, die op alle dorpen aen 's Koninghs ontfangers gelevert werden, ende tot rijst gestampt, ende nae de zeehavens op ijder Gouvernement verdeeld; sonder dat buijten deese aen ons ofte andere eenige rijst mach gelevert worden, daer voor dan de comptanten, ofte wat het zij, aen 's Koninghs tresoriers gelevert ende naer zijn hoff opgebracht werden. 'k Heb mij eens verstout den Koninck aen te raden, dat hij behoorde zijn onderdaenen te laten varen om rijck te worden, ende dat hij dan van hun conde trecken grooter gerechtichheeden, ende zijn land metter tijd soude rijck werden; doch creeg tot antwoord; mijn volck heefft als ghijlieden niets eijgen, maer alle 't hunne comt mij toe, ende sonder strenge regering soude ick geen dag Koninck zijn. Hoe streng desen barbaer zij, gelieve UEd. daer uijt te oordeelen, dat present buijten Pangeran Porbaija ende den voorgemelde Tommagon Singeranou, niemand van zijn vaders oude Raetsheeren en grooten leeft, maer zijn alle, wel tot 1000 in 't getal, daer onder mede zijn broeder ende Wiera Goena, omgebracht; behalven noch wel 2000 paepen, daer hij suspitie op hadde, dat se met zijn broeder t' samen spanden, ende niet min als 18 à 20,000 vrouwen, kinderen ende dienaers deeser grooten, alle door beuls handen omgebracht, hoewel eenige, met schijn van recht, door seer behendige en openbare middelen, te lang UEd. met die materie op te houden.

Hier voor werd UEd. toegeseijt eene aparte beschrijvinge van 't Koninckrijck Jaccatra, maer dewijl het apparent zij, dat ick daertoe beeter occasie sal becomen, om 't selve pertinenter te doen, ende sulcx nu niet volcomen can geschieden, gelieve haer Ed. met de caerten daer van overgelevert, soo lange te genoegen, tot dat de tijt beter gelegentheijd verschaffen sal. Waermede deesen sluijtende, wenschen UEd. particulier, ende alle de loffelijcke regenten van d' importante Oostindische Compe. des Heeren zeegen, die UEd. overschaduwe met wijsheid, tot uijtvoeringe van haer ampt. Amen.

$$
\text { Amsterdam, adij } 25 \text { Maart, } 1656 . \quad \text { (get.) R. v. GOENs. }
$$

